\title{
Fixation of femoral neck fractures in patients younger than 65 years: a retrospective descriptive study at a high-volume trauma centre
}

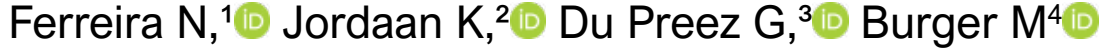

1 BSc, MBChB, FC Orth(SA), MMed(Orth), PhD; Associate professor, consultant orthopaedic surgeon and head of Tumour, Sepsis and Reconstruction Unit; Department of Surgical Sciences, Tygerberg Hospital, Stellenbosch University, Cape Town, South Africa

2 MBChB, HDip Orth(SA), FC Orth(SA); Consultant orthopaedic surgeon and head of Arthroplasty Unit; Department of Surgical Sciences, Tygerberg Hospital, Stellenbosch University, Cape Town, South Africa

${ }_{3}$ MBChB, FC Orth(SA); Consultant orthopaedic surgeon and head of Trauma; Department of Surgical Sciences, Tygerberg Hospital, Stellenbosch University, Cape Town, South Africa

4 BSc, B(Med)Sc Hons, M(Med)Sc, PhD; Researcher, Division of Orthopaedic Surgery; Department of Surgical Sciences, Tygerberg Hospital, Stellenbosch University, Cape Town, South Africa

Corresponding author: Prof. Nando Ferreira, Division of Orthopaedic Surgery, Department of Surgical Sciences, Faculty of Medicine and Health Sciences, Tygerberg Hospital, Stellenbosch University, Cape Town, 7505, South Africa; tel: +27 (21) 938 5456; email: nferreira@sun.ac.za

\begin{abstract}
Background: The management of femoral neck fractures in the younger patient remains contentious, with high failure rates being reported in the literature. Patient age usually plays a major role during decision-making with regard to head-sparing versus head-sacrificing surgical strategies. The aim of this study was to review the outcomes of fixation of femoral neck fractures in patients younger than 65 years in an attempt to identify factors that might predict fixation failure.

Methods: A retrospective study, evaluating the outcome of fixation of femoral neck fractures in patients younger than 65 years of age was conducted. Factors affecting the outcome of treatment were explored in an attempt to identify variables that might predict fixation failure.

Results: The final cohort comprised 51 men (76\%) and 16 women $(24 \%)$ with a mean age of $43.9 \pm 12.2$ years $(95 \%$ Cl $41.0-46.8$; range 23-64) and a median follow-up of 8.7 months (IQR 6.2-17.4). Thirteen patients (19\%) presented with undisplaced (Garden I and II) fractures while 54 (81\%) presented with displaced (Garden III and IV) fractures. Twenty-four patients (36\%) met the definition of failure. These included 15 cases $(22 \%)$ of non-union, seven cases $(10 \%)$ of femoral neck collapse and two cases (3\%) of avascular necrosis. Sixteen patients (24\%) underwent conversion to total hip arthroplasty. All cases of failure occurred in patients who presented with Garden III and IV displaced fractures. Factors associated with failure included the presence of fracture comminution $(p<0.001)$ and the increased vertical orientation of the fracture line according to the Pauwels classification $(p<0.001)$. Neither patient age $(p=0.117)$, time from injury to surgery $(p=0.204)$, mechanism of injury $(p=0.136)$, smoking $(p>0.999)$ nor alcohol abuse $(p=0.528)$ was associated with failure.

Conclusion: The incidence of fixation failure following surgical management of femoral neck fractures in patients younger than 65 years of age remains high. While undisplaced fractures heal readily regardless of time from injury to surgery, mechanism of injury or fixation method, displaced fractures remain a difficult problem to solve. In our series, fixation failure was observed in one in three patients, while one in four required revision to total hip arthroplasty.
\end{abstract}

Level of evidence: Level 4

Keywords: femoral neck fracture, fixation, failure, non-union, avascular necrosis

Citation: Ferreira N, Jordaan K, Du Preez G, Burger M. Fixation of femoral neck fractures in patients younger than 65 years: a retrospective descriptive study at a high-volume trauma centre. SA Orthop J 2020;19(4):200-205. http://dx.doi.org/10.17159/2309-8309/2020/v19n4a1

Editor: Prof. Sithombo Maqungo, University of Cape Town, Cape Town, South Africa

Received: April 2020

Accepted: June 2020

Published: November 2020

Copyright: $\odot 2020$ Ferreira N. This is an open-access article distributed under the terms of the Creative Commons Attribution Licence, which permits unrestricted use, distribution and reproduction in any medium, provided the original author and source are credited.

Funding: No funding has been received for this manuscript.

Conflict of interest: The authors declare they have no conflicts of interest that are directly or indirectly related to the research. 


\section{Introduction}

Femoral neck fractures are among the most frequently encountered injuries facing orthopaedic surgeons. ${ }^{1}$ The usual presentation is that of a fragility fracture in an elderly individual., 2,3 Whereas consensus has generally been reached on the management of femoral neck fractures in elderly patients, the same is not true for the management of these injuries in patients younger than 65 years..$^{4-10}$

Traditionally, the decision between head-sparing and headsacrificing procedures is based on the patient's age, fracture displacement and time from injury, where the age of the patient generally carries the most weight during decision-making. ${ }^{11,12}$ Despite the overall risk of failure being estimated at between $39 \%$ and $43 \%$, the benefit of restoring the native hip joint has been thought to outweigh the risk of failure..$^{13,14}$

The longevity of arthroplasty has been a further concern in the younger patient, adding to the call for head-sparing strategies in this population group. However, when this strategy fails, salvage arthroplasty surgery is technically more demanding and produces inferior results when compared with primary replacement. ${ }^{15-18}$

A 2018 study by Bartels et al. examined data from the Norwegian Hip Fracture Register and reported that when compared to internal fixation, patients treated with arthroplasty had fewer operations, better patient satisfaction, less pain and better quality of life. The authors suggested lowering the age at which patients with displaced intra-capsular femoral neck fractures should be considered for arthroplasty. ${ }^{19}$

Exactly how comorbid conditions like diabetes mellitus, HIV, osteoporosis, mechanism of injury and general life expectancy affect this management decision remains to be established. This study aims to present our experience of fixation of femoral neck fractures in patients younger than 65 years of age. Factors affecting the outcome of treatment were explored in an attempt to identify variables that might predict fixation failure.

\section{Methods}

A retrospective investigation of clinical records and serial radiographs of all skeletally mature patients who underwent fixation for a femoral neck fracture between January 2011 and December 2014 in a single, high-volume institution was performed. Ethical approval as well as Hospital Board approval was obtained prior to data collection.

Patients younger than 65 years, presenting with Orthopaedic Trauma Association (OTA) type $31 \mathrm{~B}$ fractures who were treated by fracture fixation were included for review. ${ }^{20}$ Pathological fractures and fractures treated by head-sacrificing procedures were excluded. Admission records were assessed for mode of injury, associated injuries and comorbid conditions. Imaging studies consisted of an antero-posterior radiograph of the pelvis as well as antero-posterior and lateral view radiographs of the affected hip. Traction view radiographs were performed where excessive shortening was encountered, and computerised tomography (CT) scans were obtained when accurate fracture configuration could not be ascertained from plain radiographs. Fracture line orientation was assessed using the annotative measurement tools of the Phillips Intellispace Picture Archiving and Communication System (PACS). Laboratory investigations comprised a full blood count, renal and liver function tests and a nutritional profile.

Surgical management consisted of either open or closed reduction followed by fixation with three cannulated screws in an inverted triangle configuration or a sliding hip screw with or without an anti-rotation cannulated screw. Open reduction was performed where a Leadbetter manoeuvre failed to produce an acceptable closed reduction and was performed through the Smith-Peterson approach. ${ }^{21,22}$ The use of a calcar plate to maintain position following open reduction was used at the discretion of the operating surgeon. The decision to use cannulated screws in an inverted triangle configuration, or in combination with a sliding hip screw, was made on the basis of bone quality; in cases with poor bone quality, a sliding hip screw in combination with an anti-rotation screw was preferred. Standard post-operative antibiotic prophylaxis consisted of 24 hours of a first-generation cephalosporin.

Outpatient follow-up consisted of a two-week, six-week, threemonth, six-month and 12-month review. At the two-week clinic follow-up, sutures were removed, and the wound inspected. Outpatient notes and follow-up radiographs were reviewed for complications experienced during healing.

Union was confirmed by a minimum score of 18 according to the Radiographic Union Score for Hip (RUSH). ${ }^{23}$ Failure was defined as any revision surgery, including re-fixation or conversion to arthroplasty, femoral neck collapse of greater than $10 \mathrm{~mm}$, any varus collapse, screw cut-out or joint penetration, as well as avascular necrosis of the femoral head.

Data was analysed using STATISTICA version 12.0 (StatSoft Inc., Tulsa, OK, USA). Captured clinical and demographic data is presented as median and interquartile ranges (IQR) for nonparametric data, and means and standard deviation for parametric data. Categorical data is presented as frequencies. Independent t-tests or Mann-Whitney $U$ tests were used to detect differences between groups for parametric and non-parametric data, respectively, while the Pearson's chi-squared or Fisher's exact test was used to detect differences between categorical variables. Significance was accepted at the $p<0.05$ level.

\section{Results}

A total of 108 patients underwent fixation for femoral neck fractures. Twenty-five patients were older than 65 years and were subsequently excluded. Sixteen patients $(19 \%)$ were lost to follow-up prior to confirmation of union or failure. The final cohort comprised 51 men (76\%) and 16 women (24\%) with a mean age of $43.9 \pm 12.2$ years $(95 \% \mathrm{Cl} 41.0-46.8$; range 23-64) (Figure 1) (Table I). The median follow-up was 8.7 months (IQR 6.2-17.4).

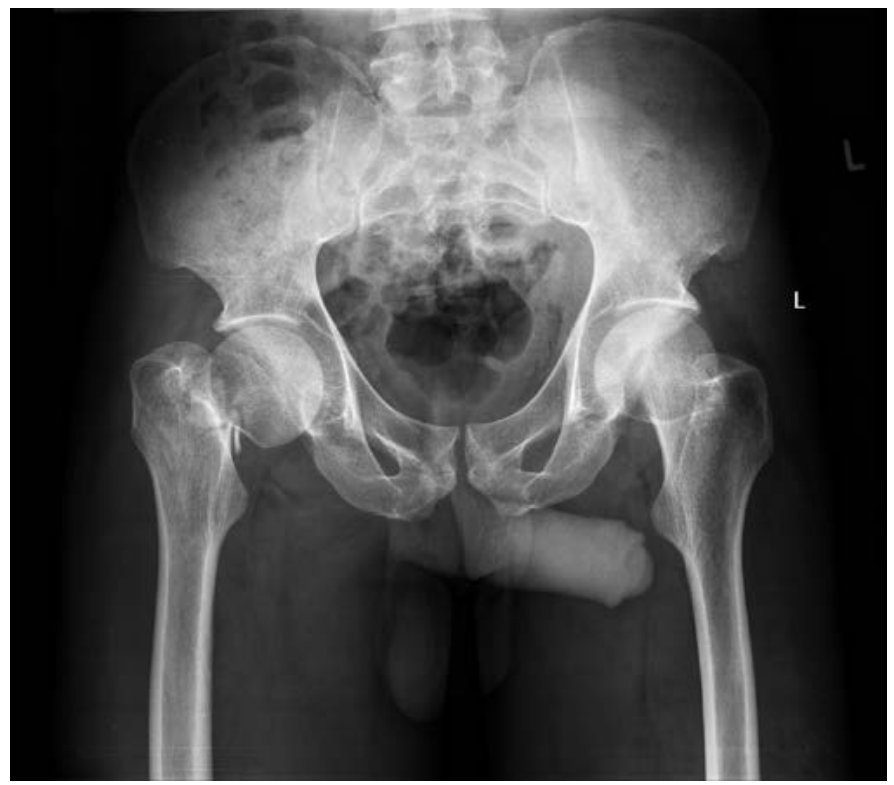

Figure 1. Antero-posterior radiograph with comminuted fracture of the right femoral neck 
Table I: General and clinical characteristics of patients

\begin{tabular}{|l|c|}
\hline & $\mathbf{n}=67$ \\
\hline Age (years) & $43.9 \pm 12.2(67)$ \\
\hline Sex (\% male) & $76 \%(51)$ \\
\hline Affected side (\% right) & $63 \%(42)$ \\
\hline Polytrauma & $16 \%(11)$ \\
\hline Mechanism of injury & \\
\hline Low energy fall & $43 \%(29)$ \\
\hline MVA/PVA & $22 \%(15)$ \\
\hline Fall from height & $18 \%(12)$ \\
\hline Gunshot & $10 \%(7)$ \\
\hline Assault & $6 \%(4)$ \\
\hline Displacement & \\
\hline Undisplaced (Garden I \& II) & $19 \%(13)$ \\
\hline Displaced (Garden III \& IV) & $81 \%(54)$ \\
\hline Follow-up time (months) & $8.7(6.2-17.4)(67)$ \\
\hline
\end{tabular}

Data is presented as mean \pm standard deviation for parametric data, median (interquartile range) for non-parametric data or frequencies, with the number of participants in parentheses. MVA: motor vehicle accident; PVA: pedestrian vehicle accident

Medical comorbidities were observed in 18 patients (27\%). These included five HIV-positive patients, two diabetic patients, four patients with confirmed cardiovascular disease and five patients with known epilepsy. All HIV-positive patients were on highly active anti-retroviral (HAART) treatment. The prevalence of these comorbidities was too low to measure association with fixation failure. Twenty-nine patients $(43 \%)$ were active smokers and $13(19 \%)$ admitted to excessive alcohol intake. Time delays between injury, admission and surgery are indicated in Table II.

Table II: Time delays between injury, admission and surgery

\begin{tabular}{|l|c|}
\hline Delays & Hours (n=67) \\
\hline Injury to admission (hours) & $12(4-26)$ \\
\hline Admission to surgery (hours) & $47(27-96)$ \\
\hline Injury to surgery (hours) & $75(46-123)$ \\
\hline
\end{tabular}

Data is presented as median (interquartile range)

Seventeen patients (25\%) required an open reduction to achieve an anatomically acceptable position. In five patients (8\%) open reduction was supplemented with a calcar plate (Figure 2). Fixation was achieved with a sliding hip screw combined with an anti-rotation cannulated screw in the majority of cases $(n=31,46 \%)$ followed by the use of cannulated screws in an inverted triangle configuration $(n=19,28 \%)$ and sliding hip screw alone $(n=16$, $24 \%)$. In one case, an undisplaced femoral neck fracture with an ipsilateral femoral shaft fracture was treated with a third-generation cephalo-medullary nail.

Twenty-four patients $(36 \%)$ met the definition of failure. These included 15 cases $(22 \%)$ of non-union, seven cases $(10 \%)$ of femoral neck collapse and two cases $(3 \%)$ of avascular necrosis. All cases of failure occurred in patients who presented with displaced fractures while no failures occurred after fixation of undisplaced fractures.

Fifty-four patients who sustained displaced fractures completed follow-up to union or failure (Table III). Fixation failure occurred in $24(44 \%)$ of these cases (Figure 3). Factors associated with failure included the presence of fracture comminution $(p<0.001)$, the vertical orientation of the fracture line according to the Pauwels

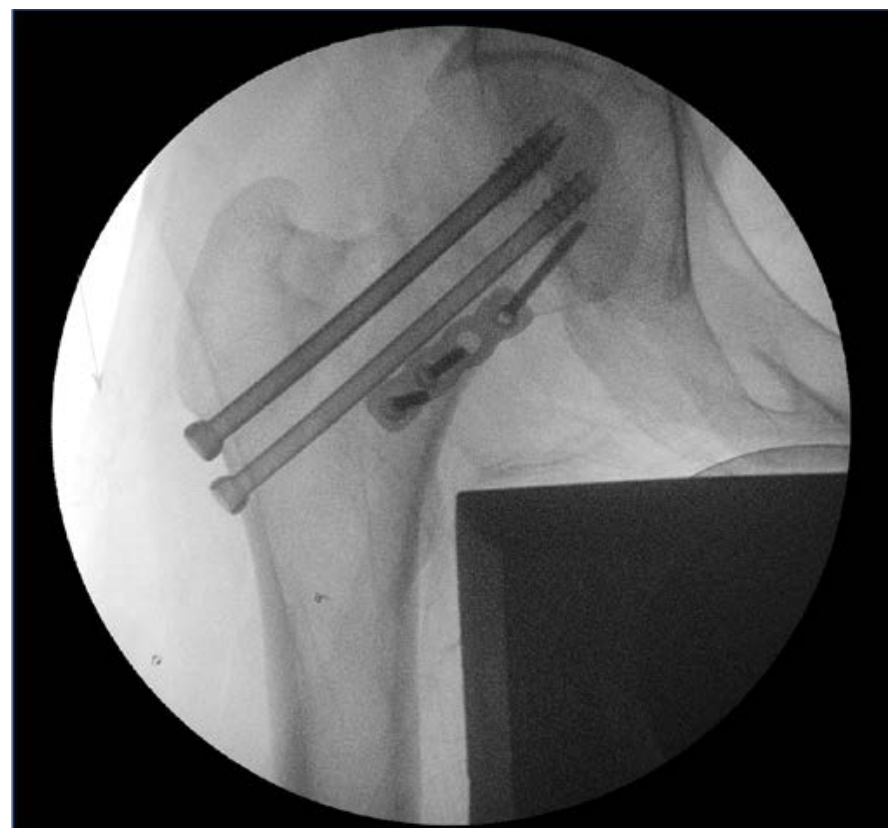

Figure 2. Intra-operative image of reduced facture with three cannulated screws and calcar plate

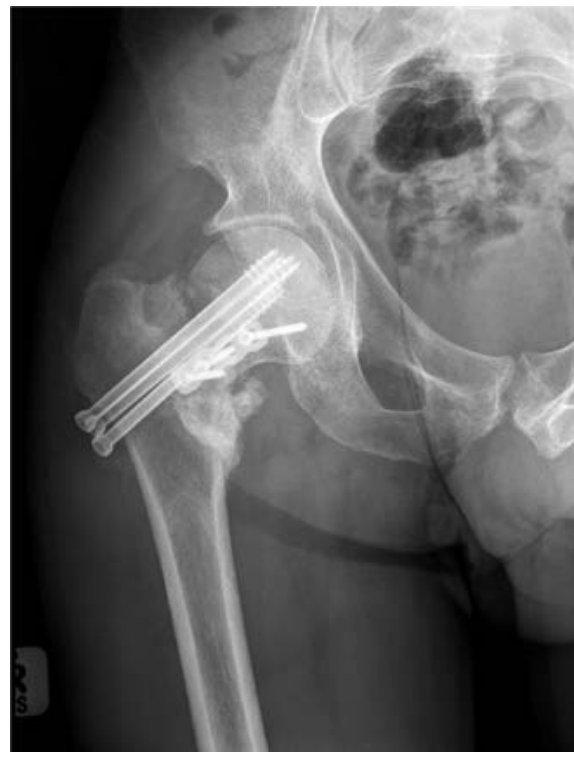

Figure 3. Anteroposterior radiograph of right hip showing non-union and fixation failure

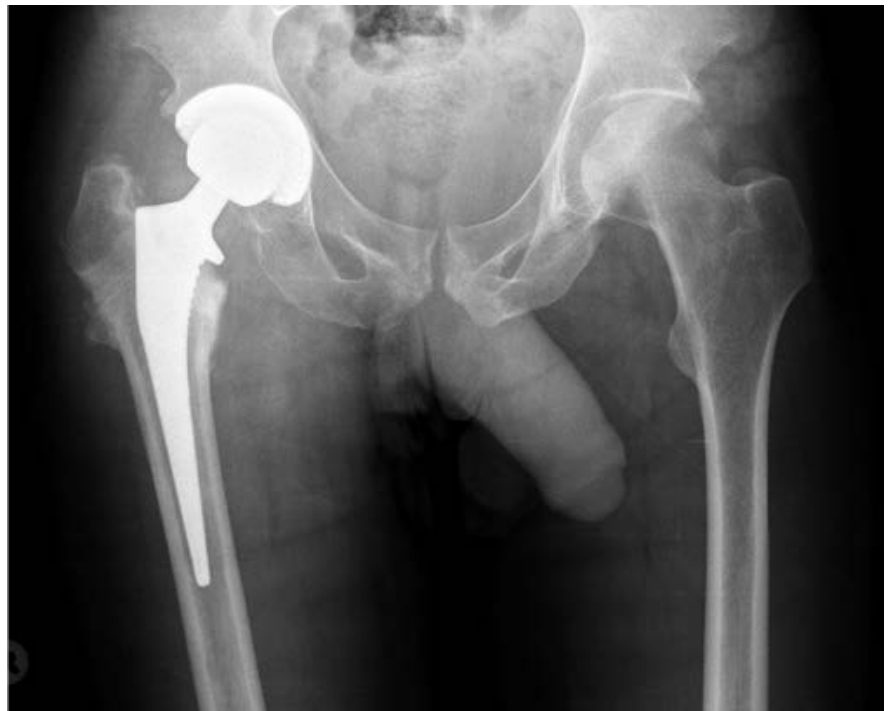

Figure 4. Antero-posterior radiograph showing conversion to right hip arthroplasty 
Table III: Details of displaced fracture cases

\begin{tabular}{|c|c|c|c|}
\hline & Failure yes $(n=24)$ & Failure no $(n=30)$ & p-value \\
\hline Age (years) & $45.9 \pm 13.0(24)$ & $40.7 \pm 10.8(30)$ & 0.117 \\
\hline Delay: injury to surgery (hours) & $83.5(44.0-120.5)(24)$ & $57.0(42.0-100.0)(30)$ & 0.204 \\
\hline \multicolumn{4}{|l|}{ Mechanism of injury } \\
\hline Low energy fall & $45(10)$ & $55(12)$ & \multirow{5}{*}{0.136} \\
\hline MVA/PVA & $29(4)$ & $71(10)$ & \\
\hline Fall from height & $36(4)$ & $64(7)$ & \\
\hline Gunshot & $75(3)$ & $25(1)$ & \\
\hline Assault & $100(3)$ & $0.0(0)$ & \\
\hline \multicolumn{4}{|l|}{ Fracture comminution } \\
\hline Yes & $94(16)$ & $6(1)$ & \multirow{2}{*}{$<0.001$} \\
\hline No & $22(8)$ & $78(29)$ & \\
\hline \multicolumn{4}{|l|}{ Pauwels classification } \\
\hline Type 1 & $0(0)$ & $100(3)$ & \multirow{3}{*}{$<0.001$} \\
\hline Type 2 & $17(2)$ & $83(10)$ & \\
\hline Type 3 & $56(22)$ & $44(17)$ & \\
\hline \multicolumn{4}{|l|}{ Smoking } \\
\hline Smoker & $46(12)$ & $54(14)$ & \multirow{2}{*}{$>0.999$} \\
\hline Non-smoker & $43(12)$ & $57(16)$ & \\
\hline \multicolumn{4}{|l|}{ Alcohol abuse } \\
\hline Yes & $54(7)$ & $46(6)$ & \multirow{2}{*}{0.528} \\
\hline No & $41(17)$ & $59(24)$ & \\
\hline \multicolumn{4}{|l|}{ Reduction } \\
\hline Open & $82(14)$ & $18(3)$ & \multirow{2}{*}{$<0.001$} \\
\hline Closed & $27(10)$ & $73(27)$ & \\
\hline \multicolumn{4}{|l|}{ Type of fixation } \\
\hline DHS \& anti-rotation screw & $46(13)$ & $54(15)$ & \multirow{4}{*}{0.744} \\
\hline DHS & $43(6)$ & $57(8)$ & \\
\hline Cannulated screws & $45(5)$ & $55(6)$ & \\
\hline Cephalomedullary nail & $0.0(0)$ & $100(1)$ & \\
\hline
\end{tabular}

Data is presented as mean \pm standard deviation, median (interquartile range) or frequencies, with the number of participants indicated in parentheses. MVA: motor vehicle accident; PVA: pedestrian vehicle accident; DHS: dynamic hip screw

classification ( $p<0.001)$, and the need for open reduction $(p<0.001)$. Neither patient age $(p=0.117)$, time from injury to surgery $(p=0.204)$, mechanism of injury $(p=0.136)$, smoking $(p>0.999)$ nor alcohol abuse $(p=0.528)$ was associated with failure.

Sixteen patients (24\%) underwent conversion to total hip arthroplasty (Figure 4). Mode of failure for patients requiring arthroplasty included 14 of the 15 cases of non-union and both patients who developed avascular necrosis. All seven cases where femoral neck collapse occurred united with resultant shortening of the femoral neck, with none of these patients requiring arthroplasty at latest follow-up.

\section{Discussion}

A recent survey among orthopaedic surgeons reported a lack of consensus in the management of femoral neck fractures in young adults and called for definitive clinical trials to resolve this issue. ${ }^{8}$ The aim of the present study was to review the outcomes of fixation of femoral neck fractures in patients younger than 65 years in an attempt to identify factors that might predict fixation failure.
It is concerning that, apart from fracture comminution and geometry, no other evaluated factors were shown to predict failure, including age, mechanism of injury, comorbidities or time from injury to fixation. These findings and similar results by other authors might demand a paradigm shift towards arthroplasty during the management of displaced femoral neck fractures in the younger patient.

Longevity of arthroplasty has remained a major concern regarding head-sacrificing strategies in the young femoral neck fracture patient, but as life expectancy varies significantly between geographic areas, the term 'young' patient should also be taken in the context of geographic location. The difference in life expectancy between Hong Kong (ranked 1) and the Central African Republic (ranked 191), for example, is almost 31 years (85.29 vs 54.36). ${ }^{24}$ Despite Norway being listed as having a life expectancy of almost 83 years (ranked 17th), Bartels et al. still suggested that patients as young as 55 years would benefit from total joint arthroplasty for displaced femoral neck fractures. ${ }^{19,24}$ It stands to reason that patients in countries with significantly lower life expectancy might potentially benefit from this approach at an even younger age. 
Stockton et al. conducted a retrospective cohort study of 796 patients between the ages of 18 and 50 years who underwent internal fixation for femoral neck fractures and found that one in three patients required a re-operation and one in seven were converted to a total hip arthroplasty. ${ }^{25}$ We observed similar outcomes, where failure was observed in one in three patients while one in four required revision to total hip arthroplasty.

In addition to non-union, fracture collapse with resultant shortening of the femoral neck was also a prominent complication seen in our series. Contradictory to Zlowodzki et al. who reported a large proportion of patients treated with cannulated screws ended with shortening, all patients who collapsed in the current cohort were treated with a sliding hip screw, with or without an anti-rotation screw. ${ }^{26}$ Despite the fact that all cases of collapse eventually united, a significant impact on physical activity can be anticipated as a result of this femoral neck shortening. ${ }^{26}$

Recent advances in implant technology has produced devices like the Targon ${ }^{\circledR} \mathrm{FN}$ (BBraun, Melsungen, Germany) and Conquest $\mathrm{FN}^{\circledR}$ (Smith \& Nephew, Memphis, TN, USA), specifically designed for fixation of femoral neck fractures. ${ }^{27}$ Both these implants are an attempt to solve the issue of non-union and fracture collapse/ implant failure. ${ }^{28-32}$ As these devices would not foreseeably alter the incidence of avascular necrosis, especially following displaced fractures, this remains an unresolved issue. With fracture collapse and non-union being observed more frequently than avascular necrosis in the current series, this new family of devices might prove beneficial, but remains to be investigated thoroughly.

Various limitations prohibit the generalisability of these results, including the retrospective nature of the study design, the small sample size and the single centre cohort which might not be representative of other centres. The results might also be skewed by the fact that nearly $20 \%$ of patients were lost to follow-up prior to confirmation of union.

\section{Conclusion}

Undisplaced femoral neck fractures in patients younger than 65 years heal readily regardless of time from injury to surgery, mechanism of injury or fixation method. Displaced fractures in the young patient remains a difficult problem to solve. In our series, fixation failure was observed in one in three patients, while one in four required revision to total hip arthroplasty. Apart from fracture comminution and geometry, no other evaluated factors were shown to predict failure, including age, mechanism of injury or time from injury to fixation.

\section{Ethics statement}

The authors declare that this submission is in accordance with the principles laid down by the Responsible Research Publication Position Statements as developed at the 2nd World Conference on Research Integrity in Singapore, 2010.

Ethical approval for this study was obtained from the Stellenbosch University Human Research Ethics Committee (N18/03/029). All procedures were in accordance with the ethical standards of the responsible committee on human experimentation (institutional and national) and with the Helsinki Declaration of 1975, as revised in 2008.

\section{Declaration}

The authors declare authorship of this article and that they have followed sound scientific research practice. This research is original and does not transgress plagiarism policies.

\section{Author contributions}

NF contributed towards study conceptualisation, acquisition, analysis and interpretation of data, first draft preparation, revision and submission of the final manuscript. KJ contributed towards study conceptualisation, data acquisition, manuscript preparation and revision, and approval of the final manuscript.

GdP contributed towards study conceptualisation, manuscript preparation and revision, and approval of the final manuscript.

MB contributed towards analysis and interpretation of the data, manuscript preparation and revision, and approval of the final manuscript.

\section{ORCID}

Ferreira N (iD https://orcid.org/0000-0002-0567-3373

Jordaan K (iD) https://orcid.org/0000-0002-6150-9463

Du Preez G (iD https://orcid.org/0000-0003-2760-7307

Burger M (D) https://orcid.org/0000-0003-2831-4960

\section{References}

1. Somersalo A, Paloneva J, Kautiainen $\mathrm{H}$, et al. Incidence of fractures requiring inpatient care. Acta Orthop. 2014;85(5):525-30.

2. Dhanwal DK, Dennison EM, Harvey NC, Cooper C. Epidemiology of hip fracture: Worldwide geographic variation. Indian J Orthop. 2011;45(1):15-22.

3. Filipov O. Epidemiology and social burden of the femoral neck fractures. J of Imab. 2014;20(4):516-18.

4. Roberts KC, Brox WT, Jevsevar DS, Sevarino K. Management of hip fractures in the elderly. J Am Acad Orthop Surg. 2015;23(2):131-37.

5. Grace L, Keller RB, Littenberg B, Wennberg JE. Outcomes after displacement fractures of the femoral neck. J Bone Joint Surg Am. 1994;76(1):15-25.

6. Miyamoto RG, Kaplan KM, Levine BR, Egol KA, Zuckerman JD. Surgical management of hip fractures: An evidence-based review of the literature. I: Femoral neck fractures. J Am Acad Orthop Surg. 2008;16(10):596-607.

7. Florschutz AV, Langford JR, Haidukewych GJ, Koval KJ. Femoral neck fractures: Current management. $J$ Orthop Trauma. 2015;23(6):460-64.

8. Slobogean GP, Sprague SA, Scott T, McKee M, Bhandari M. Management of young femoral neck fractures: Is there a consensus? Injury. 2015;46(3):435-40.

9. Ly TV, Swiontkowski MF. Treatment of femoral neck fractures in young adults. Instr Course Lect. 2009;58:69-81.

10. Chan DS. Femoral neck fractures in young patients: State of the art. J Orthop Trauma. 2019;33 Suppl 1:S7-S11.

11. Zielinski SM, Meeuwis MA, Heetveld MJ, et al. Dutch femoral neck fracture investigator group. Adherence to a femoral neck fracture treatment guideline. Int Orthop. 2013;37(7):1327-34.

12. Shah AK, Eissler J, Radomisli T. Algorithms for the treatment of femoral neck fractures. Clin Orthop Relat Res. 2002;399:28-34.

13. Lu-Yao GL, Keller RB, Littenberg B, Wennberg JE. Outcomes after displaced fractures of the femoral neck. A meta-analysis of one hundred and six published reports. J Bone Jt Surg Am. 1994;76(1):15-25.

14. Pauyo T, Drager J, Albers A, Harvey EJ. Management of femoral neck fractures in the young patient: A critical analysis review. World J Orthop. 2014;5(3):204-17.

15. Archibeck MJ, Carothers JT, Tripuraneni KR, White RE. Total hip arthroplasty after failed internal fixation of proximal femoral fractures. J Arthroplasty. 2013;28(1):168-71.

16. Morice A, Ducellier F, Bizot P. Total hip arthroplasty after failed fixation of a proximal femur fracture: Analysis of 59 cases of intra- and extra-capsular fractures. Orthop Traumatol Surg Res. 2018;104(5):681-86

17. Paley D, Herzenberg JE. Principles of deformity correction. New York: Springer-Verlag; 2001.

18. Srivastav S, Mittal V, Agarwal S. Total hip arthroplasty following failed fixation of proximal hip fractures. Indian $J$ Orthop. 2008;42(3):279-86.

19. Bartels S, Gjertsen JE, Frihagen F, Rogmark C, Utvåg SE. High failure rate after internal fixation and beneficial outcome after arthroplasty in treatment of displaced femoral neck fractures in patients between 55 and 70 years: An observational study of 2,713 patients reported to the Norwegian Hip Fracture Register. Acta Orthop. 2018;89(1):53-58.

20. Marsh JL, Slongo TF, Agel J, et al. Fracture and Dislocation Classification Compendium 2007. J Orthop Trauma. 2007;21(10 Suppl):S1-133.

21. Leadbetter GW. A treatment for fracture of the neck of the femur. Clin Orthop Relat Res. 2002;399:4-8.

22. Smith-Peterson M. A new supra-articular subperiosteal approach to the hip joint. J Bone Jt Surg Am. 1917;S2-15(8):592-95. 
23. Bhandari M, Chiavaras MM, Parasu N, et al. Radiographic Union Score for Hip substantially improves agreement between surgeons and radiologists. BMC Musculoskelet Disord. 2013;14:70.

24. No Life Expectancy of the World Population [Internet]. Available from: https://www.worldometers.info/demographics/ life-expectancy/.

25. Stockton DJ, O'Hara LM, O'Hara NN, et al. High rate of reoperation and conversion to total hip arthroplasty after internal fixation of young femoral neck fractures: a population-based study of 796 patients. Acta Orthop. 2019;90(1):21-25.

26. Zlowodzki M, Ayieni O, Petrisor BA, Bhandari M. Femoral neck shortening after fracture fixation with multiple cancellous screws: Incidence and effect on function. J Trauma. 2008;64(1):163-69.

27. Duffin M, Pilson HT. Technologies for young femoral neck fracture fixation. J Orthop Trauma. 2019;33 Suppl 1:S20-S26.

28. Xiao YP, Shu DP, Bei MJ, et al. The clinical application of a novel method of internal fixation for femoral neck fractures-dynamic locking compression system. J Orthop Surg Res. 2018;13(1):131.

29. Griffin XL, Parsons N, Achten J, Costa ML. The Targon Femoral Neck hip screw versus cannulated screws for internal fixation of intracapsular fractures of the hip: A randomised controlled trial. Bone Joint J. 2014;96-B(5):652-57.

30. Osarumwense $\mathrm{D}$, Tissingh $\mathrm{E}$, Wartenberg $\mathrm{K}$, et al. The Targon FN system for the management of intracapsular neck of femur fractures: Minimum 2-year experience and outcome in an independent hospital. Clin Orthop Surg. 2015;7(1):22-28.

31. Eschler A, Brandt S, Gierer P, Mittlmeier T, Gradl G. Angular stable multiple screw fixation (Targon FN) versus standard SHS for the fixation of femoral neck fractures. Injury. 2014;45 Suppl 1:S76-80.

32. Biber R, Brem M, Bail HJ. Targon Femoral Neck for femoral-neck fracture fixation: Lessons learnt from a series of one hundred and thirty-five consecutive cases. Int Orthop. 2014;38(3):595-99. 